\title{
Monte Carlo Based Non-Linear Mixture Model of Earth Observation Satellite Imagery Pixel Data
}

\author{
Kohei Arai ${ }^{1}$ \\ Graduate School of Science and Engineering \\ Saga University \\ Saga City, Japan
}

\begin{abstract}
Monte Carlo based non-linear mixel (mixed pixel) model of visible to near infrared radiometer of earth observation satellite imagery is proposed. Through comparative studies with actual real earth observation satellite imagery data between conventional linear mixel model and the proposed non-linear mixel model, it is found that the proposed mixel model represents the pixels in concern much precisely rather than the conventional linear mixel model.
\end{abstract}

Keywords- remote sensing satellite; visible to near infrared radiometer; mixed pixel: mixel; Monte Carlo simulation model.

\section{INTRODUCTION}

The pixels in earth observed images which are acquired with Visible to Near Infrared: VNIR sensors onboard remote sensing satellites are, essentially mixed pixels (mixels) which consists of several ground cover materials [1]. Some mixel model is required for analysis such as un-mixing of the mixel in concern [2],[3]. Typical mixel is linear mixing model which is represented by linear combination of several ground cover materials with mixing ratio for each material [4]. It is not always true that the linear mixel model is appropriate [5]. Due to the influences from multiple reflections between the atmosphere and ground, multiple scattering in the atmosphere on the observed radiance from the ground surface, pixel mixture model is essentially non-linear rather than linear. These influence is interpreted as adjacency effect [6].[7].

Method for representation of non-linear mixel model is not so easy. In particular, there is not sophisticated multi reflection model between ground materials. The representation method for non-linear mixel model is based on Monte Carlo Ray Tracing: MCRT model [8]. It is rather easy to designate surface slopes on the ground and multi reflection among trees for MCRT model. The proposed MCRT based non-linear mixel model is applied to real earth observation satellite imagery data of Advanced Spaceborn Thermal Emission and Reflection Radiometer / Visible and Near Infrared Radiometer: ASTER/VNIR onboard on Terra satellite. A comparison of radiance between the conventional linear mixel model and the proposed non-linear mixel model is conducted. As a result, validity of the proposed model is confirmed.

The following section describes the proposed non-linear mixel model based on MCRT followed by some experiments for validation of the proposed model. Then, finally, conclusions with some discussions are described.

\section{PROPOSED NON-LINEAR MIXEL MODEL}

\section{A. Monte CarloRay Tracing Simulation}

In order to show a validity of the proposed non-linear mixel model, MCRT simulation study and field experimental study is conducted. MCRT allows simulation of polarization characteristics of sea surface with designated parameters of the atmospheric conditions and sea surface and sea water conditions. Illustrative view of MCRT is shown in Fig.1.

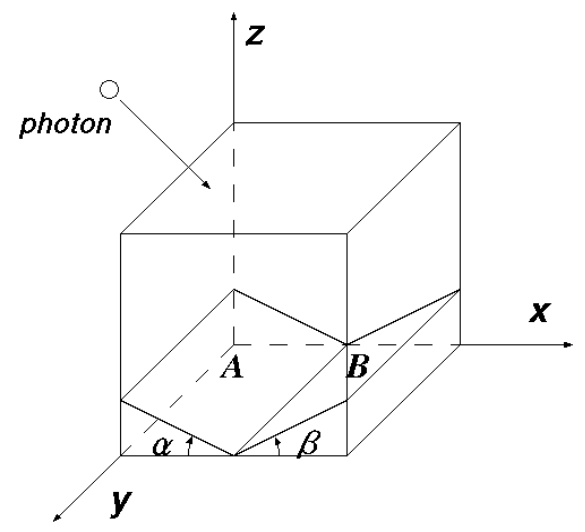

Figure 1 Illustrative view of MCRT for the atmosphere and sea water

Photon from the sun is input from the top of the atmosphere (the top of the simulation cell). Travel length of the photon is calculated with optical depth of the atmospheric molecule and that of aerosol. There are two components in the atmosphere; molecule and aerosol particles while three are also two components, water and particles; suspended solid and phytoplankton in the ocean. When the photon meets molecule or aerosol (the meeting probability with molecule and aerosol depends on their optical depth), then the photon scattered in accordance with scattering properties of molecule and aerosol. The scattering property is called as phase function ${ }^{1}$. In the visible to near infrared wavelength region, the scattering by molecule is followed by Rayleigh scattering law [10] while that by aerosol is followed by Mie scattering law [10]. Example of phase function of Mie scattering is shown in Fig.2 (a) while that of Rayleigh scattering is shown in Fig.2 (b).

\footnotetext{
${ }^{1}$ http://ejje.weblio.jp/content/phase+function
} 

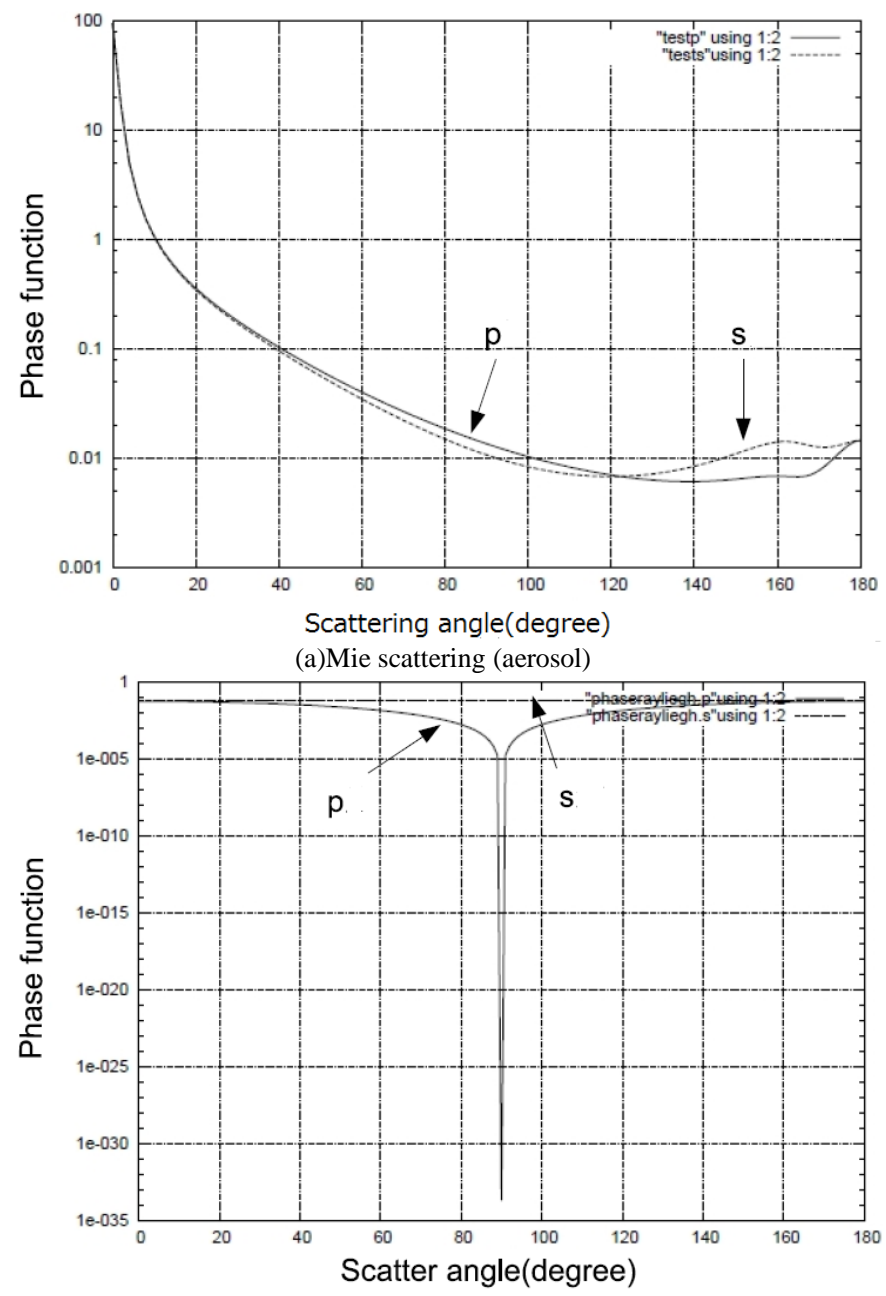

(b)Rayleigh scattering (Molecule)

Figure 2 Phase functions for Mie and Rayleigh scattering

In the atmosphere, there are absorption due to water vapor, ozone and aerosols together with scattering due to the atmospheric molecules, aerosols. Atmospheric Optical Depth: AOD (optical thickness) in total, Optical Depth: OD due to water vapor $\left(\mathrm{H}_{2} \mathrm{O}\right)$, ozone $\left(\mathrm{O}_{3}\right)$, molecules (MOL), aerosols (AER), and real observed OD (OBS) are plotted in Fig.3 as an example.

For simplifying the calculations of the atmospheric influences, it is assumed that the atmosphere containing only molecules and aerosols. As shown in Fig.3, this assumption is not so bad. Thus the travel length of the photon at once, $L$ is expressed with equation (1).

$L=L_{0} \operatorname{RND}(i)$

$L_{0}=Z_{\max } / \tau$

where $Z_{\max }, \tau, \operatorname{RND}(i)$ are maximum length, altitude of the atmosphere, optical depth, and $i$-th random number, respectively. In this equation, $\tau$ is optical depth of molecule or aerosol. The photon meets molecule when the random number is greater than $\tau$. Meanwhile, if the random number is less than $\tau$, then the photon meats aerosol. The photon is scattered at the molecule or aerosol to the direction which is determined with the aforementioned phase function and with the rest of the travel length of the photon.

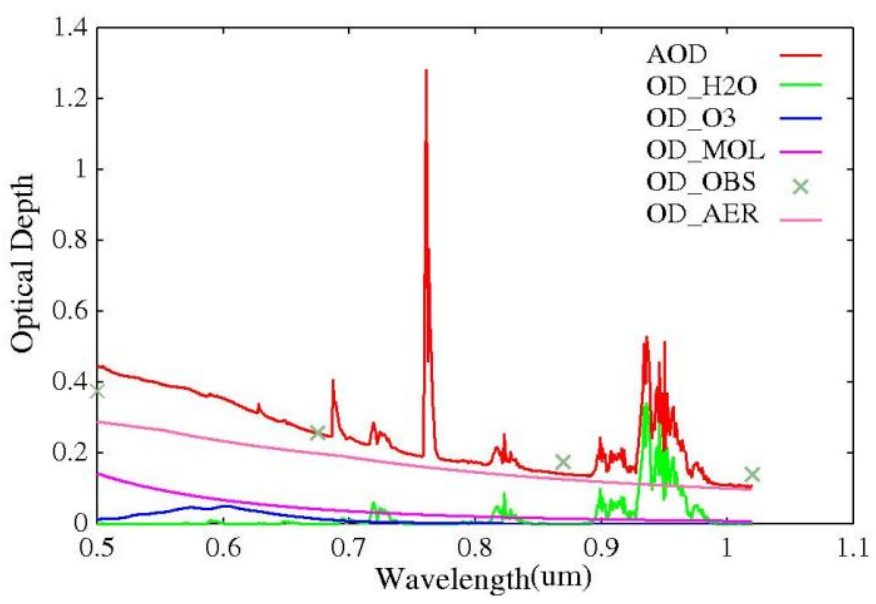

Figure 3 Example of observed atmospheric optical depth in total and the best fit curves of optical depth due to water vapor, ozone, molecules, and aerosols calculated with MODTRAN of atmospheric radiative transfer software code..

\section{B. Ground Surface with Slopes}

When the photon reaches on the ground, the photon reflects at the ground surface to the direction which is determined by random number. Lambertian surface [11] is assumed. Therefore, reflectance is constant for all the directions. The reflected photon travels with the rest of travel length. Two adjacent slopes of Lambertian surfaces are assumed on the ground as shown in Fig.4. Slope angles for both are $\alpha, \beta$ while their reflectance are $\Gamma_{A}$ and $\Gamma_{B}$

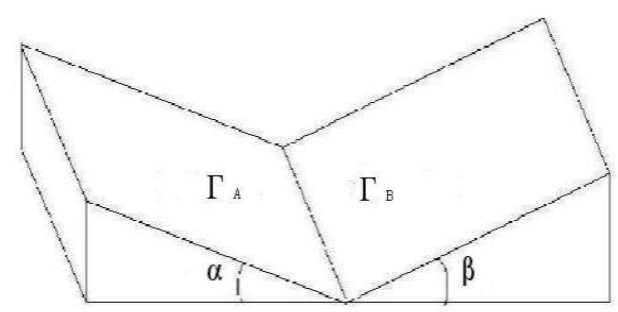

Figure 4 Two adjacent slopes of Lambertian surfaces which are assumed on the ground

\section{Top of the Atmosphere: TOA Radiance Calculation}

If the photon reaches on the wall of the simulation cell, the photon disappears at the wall and it appears from the corresponding position on the opposite side wall. Then it travels with the rest of travel length. Eventually, the photons which are reached at the top of the atmosphere are gathered with the Instantaneous Field of View: IFOV of the Visible to Near Infrared Radiometer: VNIR onboard satellite. At sensor radiance, $\mathrm{I}^{+}$with direction and IFOV of $\mu, \mu_{0}$ can be calculated with equation (3)

$I^{+}\left(\mu, \mu_{0}\right)=I N^{+}\left(\mu, \mu_{0}\right) / N_{\text {total }}$

where $N^{+}$is the number of photons which are gathered by VNIR, $N_{\text {total }}$ denotes the number of photons input to the simulation cell. Also $I$ denote extraterrestrial irradiance at the top of the atmosphere. 


\section{EXPERIMENTS}

\section{A. Validity of the Monte CarloRay Tracing Simulation}

In order to confirm that the developed MCRT is valid, a comparative study is conducted between radiative transfer code of Gauss Seidel method and the MCRT derived TOA radiance. Because the Gauss Seidel method allows calculation of TOA radiance with flat surface of ground, 0.2 of reflectance of flat surface is assumed in the comparison. Also, 0.02 and 0.03 of optical depths are assumed for aerosol and molecule.

The size of simulation cell is determined as $50 \mathrm{~km}$ by 50 $\mathrm{km}$ by $50 \mathrm{~km}$. Solar zenith angle is set at 30 degree while solar azimuth is set at 120 degree. 700,000 of photons are input to the simulation cell. TOA radiance derived from the Gauss Seidel method is $0.565\left(\mathrm{~mW} / \mathrm{m}^{2} / \mathrm{sr} / \mu \mathrm{m}\right)$ while that from the MCRT is $0.579\left(\mathrm{~mW} / \mathrm{m}^{2} / \mathrm{sr} / \mu \mathrm{m}\right)$ at the $500 \mathrm{~nm}$ of wavelength. For both cases, IFOV of the VNIR radiometer is assumed to be $2 \pi$, all of the photons output from the top of the atmosphere are counted. Therefore, the developed MCRT seems valid enough.

\section{B. TOA Radiance for the Different Combination of Optical}

Depths of Aerosol and Molecule and for the Ground with the Different Slopes

TOA radiance at $500 \mathrm{~nm}$ of wavelength for the different combination of optical depths of aerosol and molecule which ranges from 0.01 to 0.04 and for the ground with the different slopes, 0 and 20 degree are calculated.

Again, IFOV of the VNIR radiometer is assumed to be $2 \pi$, all of the photons output from the top of the atmosphere are counted. The reflectance for both slopes are same as 0.5. The results are shown in Table 1 . In the table, $\tau_{\text {aer }}, \tau_{m o l}$ are optical depths of aerosol and molecule, respectively.

TABLE I. TOP OF THE ATMOSPHERE: TOA RADIANCE FOR THE COMBINATIONS OF ATMOSPHERIC CONDITIONS

\begin{tabular}{|r|r|r|r|r|}
\cline { 2 - 5 } \multicolumn{1}{c|}{} & \multicolumn{4}{|c|}{ TOA radiance $\left(\mathrm{mW} / \mathrm{m}^{2} / \mathrm{sr} / \mu \mathrm{m}\right)$} \\
\hline$\tau_{\text {aer }} \backslash \tau_{\text {mol }}$ & 0.01 & 0.02 & 0.03 & 0.04 \\
\hline 0.01 & 3.51 & 0.317 & 3.99 & 6.51 \\
\hline 0.02 & 5.65 & 1.91 & 1.09 & 3.04 \\
\hline 0.03 & 5.7 & 3.08 & 0.622 & 10.7 \\
\hline 0.04 & 3.29 & 3.85 & 3.97 & 7.45 \\
\hline
\end{tabular}

\section{Validity of the Proposed Non-Linear Mixel Model with Real VNIR Data}

The proposed non-linear mixel model based on MCRT is validated with real earth observation satellite imagery data of ASTER/VNIR onboard Terra satellite which is acquired at 11:09 Japanese Standard Time: JST on December 152004. IFOV of ASTER/VNIR is $15 \mathrm{~m}$ with $60 \mathrm{~km}$ of swath width. Whole scene of ASTER/VNIR is shown in Fig.5 (a) while Fig.5 (b) shows a portion of the scene.

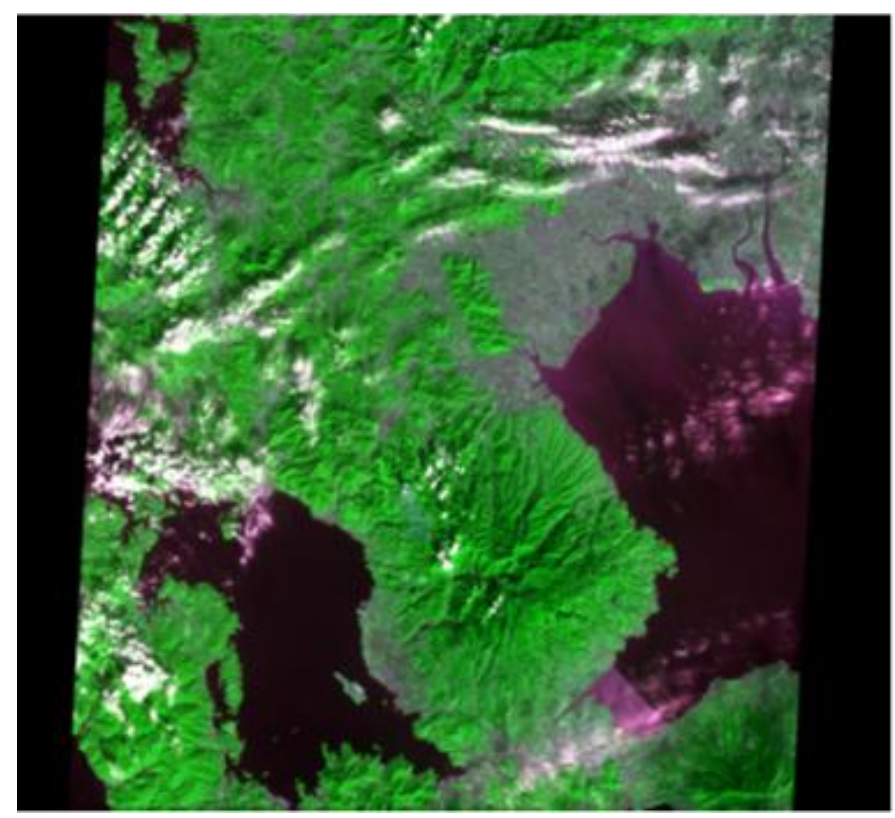

(a)Whole scene of ASTER/VNIR image

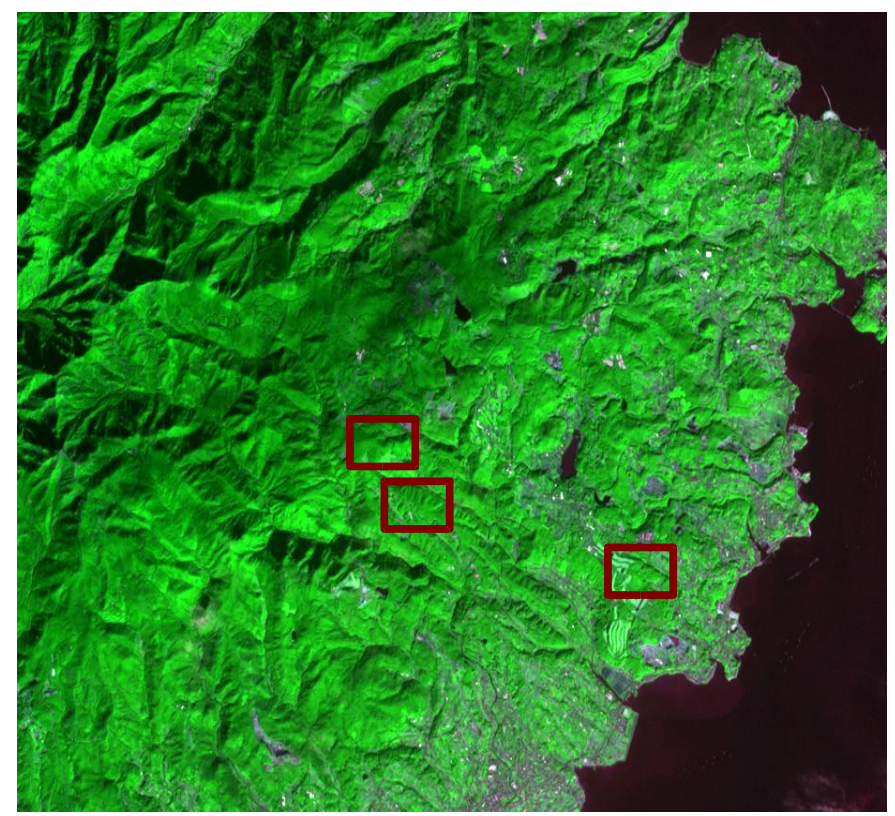

(b)A portion of the scene

Figure 5 ASTER/VNIR image used for experiment

Three test sites, Area \#1, 2, 3 are extracted from the scene. Attribute information of these sites are listed in Table 2.

Fig.6 (a) shows three test sites on ASTER/VNIR image while Fig.6 (b) shows three test sites on Google map. Other than these, topographic map of three test sites which is corresponding to the Google map is shown in Fig.6 (c) while the extracted portion of each test site on ASTER/VNIR image is shown in Fig.6 (d), (e) and (f), respectively. These digital elevation models for three test sites are taken into account in the MCRT simulations. 
Also, solar zenith angle of 58 degree and solar azimuth angle of 17 degree are taken into account in the simulations. From the atmospheric optical depth measurement data with sun photometer, optical depth of total atmosphere is calculated.

TABLE II. ATtRIBUtions FOR THE TEST Site WITH SLOPES

\begin{tabular}{|c|c|c|c|}
\hline & Area \#1 & Area \#2 & Area \#3 \\
\hline Area Name & $\begin{array}{l}\text { Korai-cho, } \\
\text { Ochiai-gawa }\end{array}$ & $\begin{array}{l}\text { Korai-cho, } \\
\text { Ochiai-gawa }\end{array}$ & $\begin{array}{l}\text { Konagai Golf } \\
\text { Club }\end{array}$ \\
\hline Latitude & $32^{\circ} 57^{\prime} 30^{\prime \prime}$ & $32^{\circ} 56^{\prime} 33^{\prime \prime}$ & $32^{\circ} 56^{\prime} 13^{\prime \prime}$ \\
\hline Longitude & $130^{\circ} 7^{\prime} 19^{\prime \prime}$ & $130^{\circ} 7 ' 25^{\prime \prime}$ & $130^{\circ} 10^{\prime} 21^{\prime \prime}$ \\
\hline Slope $A\left(^{\circ}\right)$ & 24 & 30 & 20 \\
\hline Slope $\mathrm{B}\left({ }^{\circ}\right)$ & 28 & 26 & 0 \\
\hline$\Gamma_{A}$ & 0.14 & 0.2 & 0.14 \\
\hline Material & Deciduous & Bare Soil & Deciduous \\
\hline$\Gamma_{B}$ & 0.08 & 0.08 & 0.12 \\
\hline Material & Coniferous & Coniferous & Paddy \\
\hline OD-Aerosol & 0.35 & 0.35 & 0.35 \\
\hline OD-Molecule & 0.14 & 0.14 & 0.14 \\
\hline
\end{tabular}

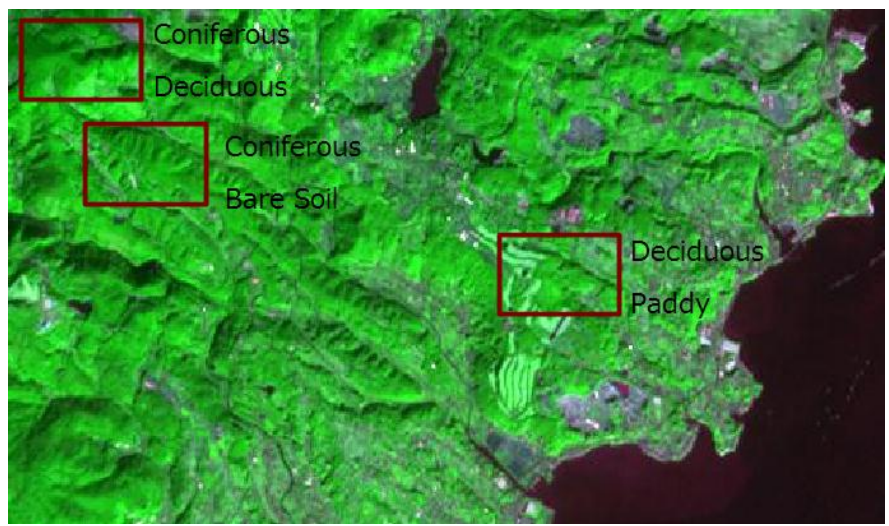

(a)Three test sites on ASTER/VNIR image

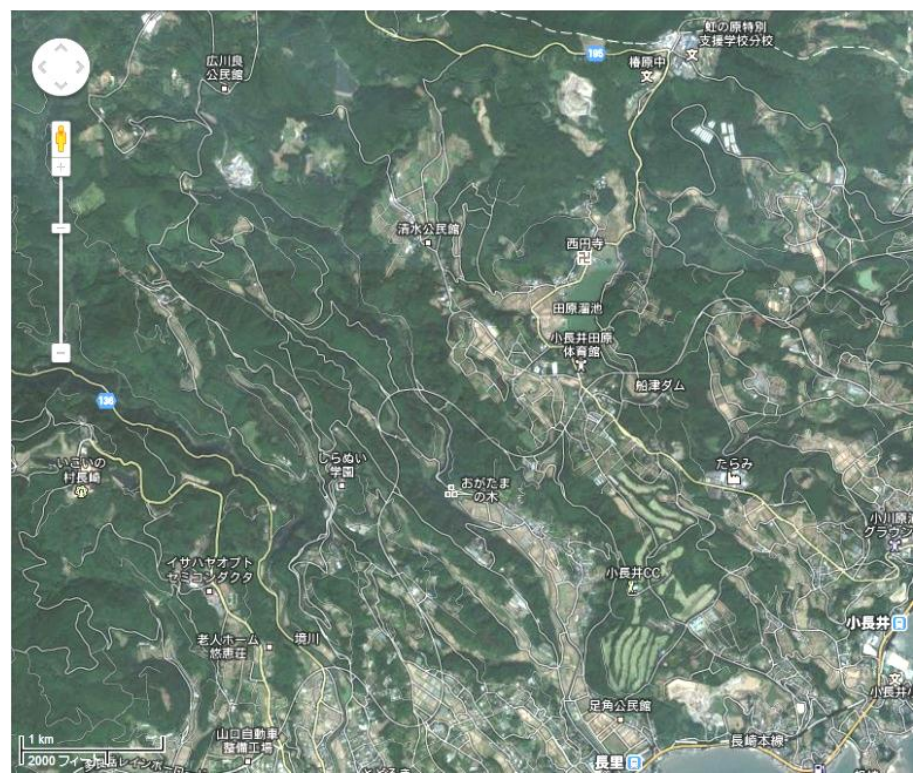

(b)Three test sites on Google Map

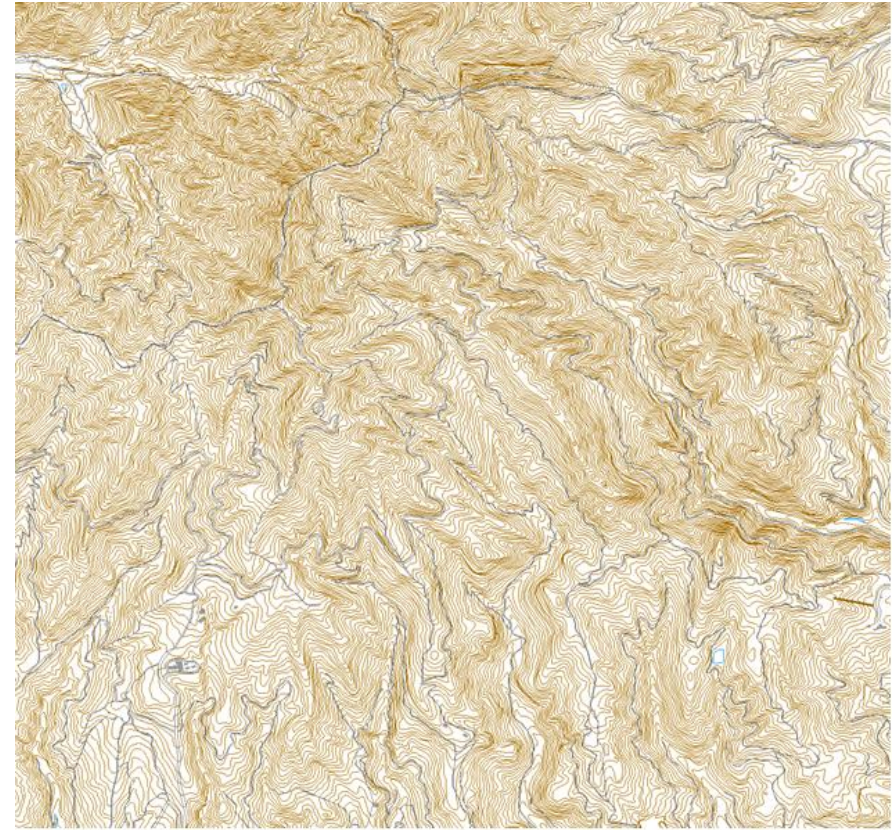

(c) Topographic map of corresponding area of three test sites on Google map

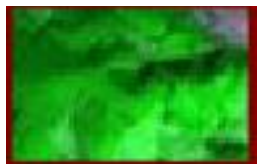

Coniferous (above), Deciduous (bottom)

(d)Area\#1 (Korai-cho, Ochiai-gawa, Nagasaki, Japan)

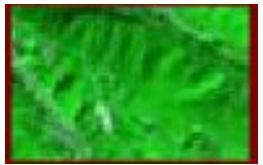

Coniferous (above), Bare Soil (bottom)

(e)Area \#2 (Korai-cho, Ochiai-gawa, Nagasaki, Japan)

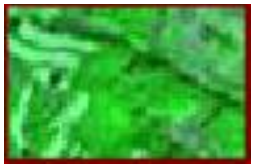

Deciduous (above), Paddy field (bottom)

(f)Area \#3 (Konagai Country Club, Nagasaki, Japan)

Figure 6 Three test site, Area \#1, 2, 3.

Furthermore, molecule optical depth $\tau_{R}$ is calculated with equation (4) as a function of atmospheric pressure $\mathrm{P}$ which is measured on the ground.

$$
\tau_{R}(\lambda)=\frac{P}{P_{0}} \cdot 0.00864 \lambda^{-\left(3.916+0.074 \lambda+\frac{0.05}{\lambda}\right)}
$$

where $P_{0}$ denotes standard atmospheric pressure on the ground $(1013 \mathrm{hPa})$ while $\lambda$ denotes wavelength. Then aerosol optical depth is calculated from total atmospheric optical depth by subtracting molecule optical depth. 
Comparative study is conducted between ASTER/VNIR derived radiance of Band 2 (Green band) and the radiance which derived from the conventional linear mixel model and the proposed non-linear mixel model.

Table 3 shows the calculated radiance in unit of $\mu \mathrm{W} / \mathrm{m}^{2} / \mathrm{sr} / \mu \mathrm{m}$ and the radiance difference between ASTER/VNIR and the estimated with the conventional and the proposed mixel models.

TABLE III. COMPARISON OF RADIANCE BETWEEN REAL ASTER/VNIR AND THE CONVENTIONAL Linear MiXel MODEl aS WELl AS THE PROPOSED NON-LiNEAR MiXEL MODEL DERIVED RADIANCE

\begin{tabular}{|l|r|r|r|}
\hline & Area \#1 & Area \#2 & Area \#3 \\
\hline ASTER/VNIR & 14.1 & 15.5 & 16 \\
\hline Linear & 12.9 & 13.7 & 14.6 \\
\hline Non-Linear & 13.7 & 14.3 & 15 \\
\hline VNIR-Linear & 1.2 & 1.8 & 1.4 \\
\hline VNIR-Non-Linear & 0.4 & 1.2 & 1 \\
\hline
\end{tabular}

It is found that the estimated radiance with the proposed non-linear mixel model is much closer rather than that with the conventional linear mixel model.

\section{CONCLUSION}

Monte Carlo based non-linear mixel (mixed pixel) model of visible to near infrared radiometer of earth observation satellite imagery is proposed. Through comparative studies between ASTER/VNIR derived radiance and the conventional linear mixel model derived radiance as well as the proposed non-linear mixel model derived radiance, it is found that the estimated radiance with the proposed non-linear mixel model is much closer to ASTER/VNIR derived radiance (around 6\%) rather than that with the conventional linear mixel model.

One of the disadvantages of the proposed non-linear mixel model based on MCRT is time consumable computations. Acceleration is highly required.

\section{ACKNOWLEDGMENT}

The author would like to thank Dr. Yasunori Terayama and Mr. Kohei Imaoka of Saga University for their effort to simulation study and experiments.

\section{REFERENCES}

[1] Masao Matsumoto, Hiroki Fujiku, Kiyoshi Tsuchiya, Kohei Arai, Category decomposition in the maximum likelihood classification, Journal of Japan Society of Phtogrammetro and Remote Sensing, 30, 2, 25-34, 1991

[2] Masao Moriyama, Yasunori Terayama, Kohei Arai, Clafficication method based on the mixing ratio by means of category decomposition, Journal of Remote Sensing Society of Japan, 13, 3, 23-32, 1993.

[3] Kohei Arai and H.Chen, Unmixing method for hyperspectral data based on subspace method with learning process, Techninical Notes of the Science and Engineering Faculty of Saga University,, 35, 1, 41-46, 2006.

[4] Kohei Arai and Y.Terayama, Label Relaxation Using a Linear Mixture Model, International Journal of Remote Sensing, 13, 16, 3217-3227, 1992.

[5] Kohei Arai, Yasunori Terayama, Yoko Ueda, Masao Moriyama, Cloud coverage ratio estimations within a pixel by means of category decomposition, Journal of Japan Society of Phtogrammetro and Remote Sensing, 31, 5, 4-10, 1992.

[6] Kohei Arai, Non-linear mixture model of mixed pixels in remote sensing satellite images based on Monte Carlo simulation, Advances in Space Research, 41, 11, 1715-1723, 2008.

[7] Kohei Arai, Kakei Chen, Category decomposition of hyper spectral data analysis based on sub-space method with learning processes, Journal of Japan Society of Phtogrammetro and Remote Sensing, 45, 5, 23-31, 2006.

[8] Kohei Arai, Adjacency effect of layered clouds estimated with MonteCarlo simulation, Advances in Space Research, Vol.29, No.19, 18071812, 2002.

[9] Ramachandran, Justice, Abrams(Edt.),Kohei Arai et al., Land Remote Sensing and Global Environmental Changes, Part-II, Sec.5: ASTER VNIR and SWIR Radiometric Calibration and Atmospheric Correction, 83-116, Springer 2010.

[10] Kohei Arai, Lecture Note for Remote Sensing, Morikita Publishing Inc., (Scattering), 2004.

[11] Kohei Arai, Fundamental Theory for Remote Sensing, Gakujutsu-Tosho Publishing Co., Ltd.,(Lambertian), 2001.

\section{AUTHORS PROFILE}

Kohei Arai, He received BS, MS and PhD degrees in 1972, 1974 and 1982, respectively. He was with The Institute for Industrial Science, and Technology of the University of Tokyo from 1974 to 1978 also was with National Space Development Agency of Japan (current JAXA) from 1979 to 1990. During from 1985 to 1987, he was with Canada Centre for Remote Sensing as a PostDoctoral Fellow of National Science and Engineering Research Council of Canada. He was appointed professor at Department of Information Science, Saga University in 1990. He was appointed councilor for the Aeronautics and Space related to the Technology Committee of the Ministry of Science and Technology during from 1998 to 2000. He was also appointed councilor of Saga University from 2002 and 2003 followed by an executive councilor of the Remote Sensing Society of Japan for 2003 to 2005 . He is an adjunct professor of University of Arizona, USA since 1998. He also was appointed vice chairman of the Commission "A" of ICSU/COSPAR in 2008. He wrote 30 books and published 332 journal papers. 